Ambiente \& Água - An Interdisciplinary Journal of Applied Science
ISSN 1980-993X - doi:10.4136/1980-993X
www.ambi-agua.net
E-mail: ambi-agua@agro.unitau.br

\title{
Hidroquímica do carbonato e bicarbonato: efeito na qualidade de águas subterrâneas em Crateús, Ceará, Brasil
}

\author{
doi: 10.4136/ambi-agua.1405 \\ Received: 25.May 2014; Accepted: 20 Jul. 2014 \\ José Ossian Gadelha de Lima*; Francisco das Chagas da Costa Lopes; \\ Jonas Rodrigues Lima \\ Universidade Estadual do Ceará (UECE), Crateús, CE, Brasil \\ *Autor correspondente: e-mail: jose.lima@uece.br, \\ fclopescosta@bol.com.br, jrlquimica@gmail.com
}

\section{RESUMO}

O município de Crateús está localizado na região semiárida do Nordeste do Brasil, onde as condições climáticas provocam escassez hídrica e baixa qualidade nas águas disponíveis. Este trabalho teve por objetivo estudar, durante um ano, o comportamento do $\mathrm{pH}$ e das concentrações dos íons carbonato $\left(\mathrm{CO}_{3}{ }^{2-}\right)$ e bicarbonato $\left(\mathrm{HCO}_{3}{ }^{-}\right)$nas águas de oito poços utilizadas para irrigação de pequenas culturas e consumo doméstico. Os resultados mostraram que nenhuma das amostras apresentou valor de $\mathrm{pH}$ que comprometesse sua qualidade, tanto para uso na irrigação, quanto para consumo humano. No entanto, os íons bicarbonato e carbonato apresentaram grau de restrição que varia de leve a severo. Portanto, seu uso na agricultura demanda monitoramento e cuidados rigorosos para amenizar os efeitos negativos na produtividade e no solo.

Palavras-chave: parâmetros, poços amazonas, recursos hídricos, técnicas de manejo.

\section{Hydrochemistry of carbonate and bicarbonate: effect on groundwater quality in Crateús, Ceará, Brazil}

\begin{abstract}
The city of Crateús is located in the semi-arid region of northeastern Brazil, where climatic conditions cause water scarcity and low quality of available water. This work was a one year study of the behavior of $\mathrm{pH}$ and concentrations of carbonate $\left(\mathrm{CO}_{3}{ }^{2-}\right)$ and bicarbonate $\left(\mathrm{HCO}_{3}{ }^{-}\right)$ions in the waters of eight wells used for irrigation of small crops and domestic consumption. The results showed that none of the samples had $\mathrm{pH}$ values that compromised their quality, both for use in irrigation and for human consumption. However, carbonate and bicarbonate ions presented restrictions that varied from mild to severe. Therefore, its use in agriculture requires rigorous monitoring and care to mitigate the negative effects on productivity and soil.
\end{abstract}

Keywords: parameters, piezometric wells, water resources, management techniques. 


\section{INTRODUÇÃO}

Embora em grande abundância, apenas uma pequena porcentagem da água do nosso planeta é potável. Apesar desta pouca disponibilidade, a humanidade polui alguns mananciais que são fontes importantes desses recursos, como os rios, nascentes, lagos, aquíferos e outros reservatórios (Todd e Mays, 2005). A despeito da grande quantidade de água superficial disponível no território brasileiro, populações de algumas regiões do Brasil, como a do Nordeste, sofrem com a escassez de água potável para consumo, principalmente nos períodos de seca (Rebouças, 1997). Soma-se ao problema da escassez, a má qualidade dos poucos recursos hídricos disponíveis, muitas vezes devido ao alto grau de sais neles dissolvidos (Lima et al., 2014).

Enfrentada pelos habitantes da zona rural de Crateús, município situado em pleno semiárido cearense, esta problemática se agrava pela completa falta de conhecimento da população sobre a qualidade das águas encontradas nas poucas fontes disponíveis (Silva Júnior et al., 1999). As águas subterrâneas explotadas de poços do tipo amazonas desempenham papel importante, pois são as únicas fontes que atendem às famílias, usadas na maioria das atividades domésticas e na irrigação de pequenas culturas (Tucci et al., 2000).

Para avaliar a qualidade da água subterrânea é necessário conhecer os parâmetros físicos e químicos que a caracterizam. Alguns aspectos da qualidade estão relacionados ao $\mathrm{pH}$ e à concentração dos íons carbonato $\left(\mathrm{CO}_{3}{ }^{2-}\right)$ e bicarbonato $\left(\mathrm{HCO}_{3}{ }^{-}\right)$(Alvarenga et al., 2012). $\mathrm{O}$ $\mathrm{pH}$ é controlado por reações e por equilíbrio entre os íons presentes. A maioria das águas subterrâneas tem $\mathrm{pH}$ entre 5,5 e 8,5 e, em casos excepcionais, pode variar de 3,0 a 11,0 (Santos, 2008).

A quantidade relativa de íons carbonato em uma água é função do $\mathrm{pH}$ e do conteúdo de gás carbônico dissolvido. Em águas naturais doces, a quantidade deste íon é muito baixa em comparação com a do bicarbonato. $\mathrm{O}$ íon carbonato é indesejável em águas destinadas a irrigação, pois sua presença na forma de carbonato de sódio $\left(\mathrm{Na}_{2} \mathrm{CO}_{3}\right)$ é altamente tóxica para os vegetais. Quando o pH é igual ou superior a 10, a concentração do íon carbonato excede a do íon bicarbonato (Neven, 2006).

O íon bicarbonato não se oxida nem se reduz em águas naturais, porém pode precipitar com muita facilidade como carbonato de cálcio $\left(\mathrm{CaCO}_{3}\right)$. Quando sua concentração é inferior a $91,5 \mathrm{mg} \mathrm{L}^{-1}$, é benéfico aos vegetais, principalmente na forma de bicarbonato de cálcio $\left[\mathrm{Ca}\left(\mathrm{HCO}_{3}\right)_{2}\right]$ (Zoby e Oliveira, 2005). Segundo Santos (2008), a concentração desse íon varia de 50,0 a 350,0 $\mathrm{mg} \mathrm{L}^{-1}$ em águas doces, podendo chegar a $800,0 \mathrm{mg} \mathrm{L}^{-1}$.

Segundo Ayers e Westcot (1994) e Almeida (2010), água com pH na faixa de 6,5 a 8,4 é considerada normal e, portanto, não apresenta restrições de uso na irrigação. Água com concentração de carbonato menor que $3,0 \mathrm{mg} \mathrm{L}^{-1}$ não apresenta restrições de uso; se tiver de 3,0 a 6,0 $\mathrm{mg} \mathrm{L}^{-1}$, apresenta grau de restrição de leve a moderado; e se esse valor for acima de $6,0 \mathrm{mg} \mathrm{L} \mathrm{L}^{-1}$, apresenta grau de restrição severo. Quando a concentração do bicarbonato for menor que $91,5 \mathrm{mg} \mathrm{L}^{-1}$, não há restrições de uso; entre 91,5 e $518,5 \mathrm{mg} \mathrm{L}^{-1}$, o grau de restrição é de leve a moderado; acima de $518,5 \mathrm{mg} \mathrm{L}^{-1}$, tem severo grau de restrição de uso.

Segundo Almeida (2010), águas com grau de restrição de leve a moderado e severo podem ocasionar sérios riscos de entupimento para os sistemas de irrigação, além de provocar graves prejuízos na produtividade das culturas com elas irrigadas, devido aos danos causados à planta e ao solo.

Quanto ao uso para consumo humano, a Portaria $n^{0}$ 2.914/11 do Ministério da Saúde recomenda que a água apresente valores de $\mathrm{pH}$ entre 6,0 e 9,5, mas não faz referência aos teores de íons carbonato e bicarbonato (Brasil, 2011).

O objetivo deste trabalho foi estudar, utilizando análises físico-químicas, durante o período de um ano, o comportamento do $\mathrm{pH}$ e das concentrações dos íons carbonato e 
bicarbonato presentes em águas de oito poços amazonas localizados no município de Crateús, utilizadas para consumo doméstico e irrigação de pequenas culturas familiares.

\section{MATERIAIS E MÉTODOS}

\section{1. Área de estudo}

O município de Crateús está localizado na microrregião do Sertão de Crateús (coordenadas geográficas: S 5 $5^{\circ} 10^{\prime} 33,3$ ', e O 40 40' 42' '), na porção centro-oeste do Estado do Ceará (Figura 1). Sua área territorial compreende $2.985,411 \mathrm{~km}^{2}$ e faz parte da Depressão Sertaneja, um pediplano típico da região semiárida do Nordeste brasileiro (Feitosa, 1998; Brasil, 2010).

No quadro geológico do município predomina rochas do embasamento cristalino pré-cambriano, na forma de gnaisses, quartzitos e migmatitos (Lima et al., 2014).

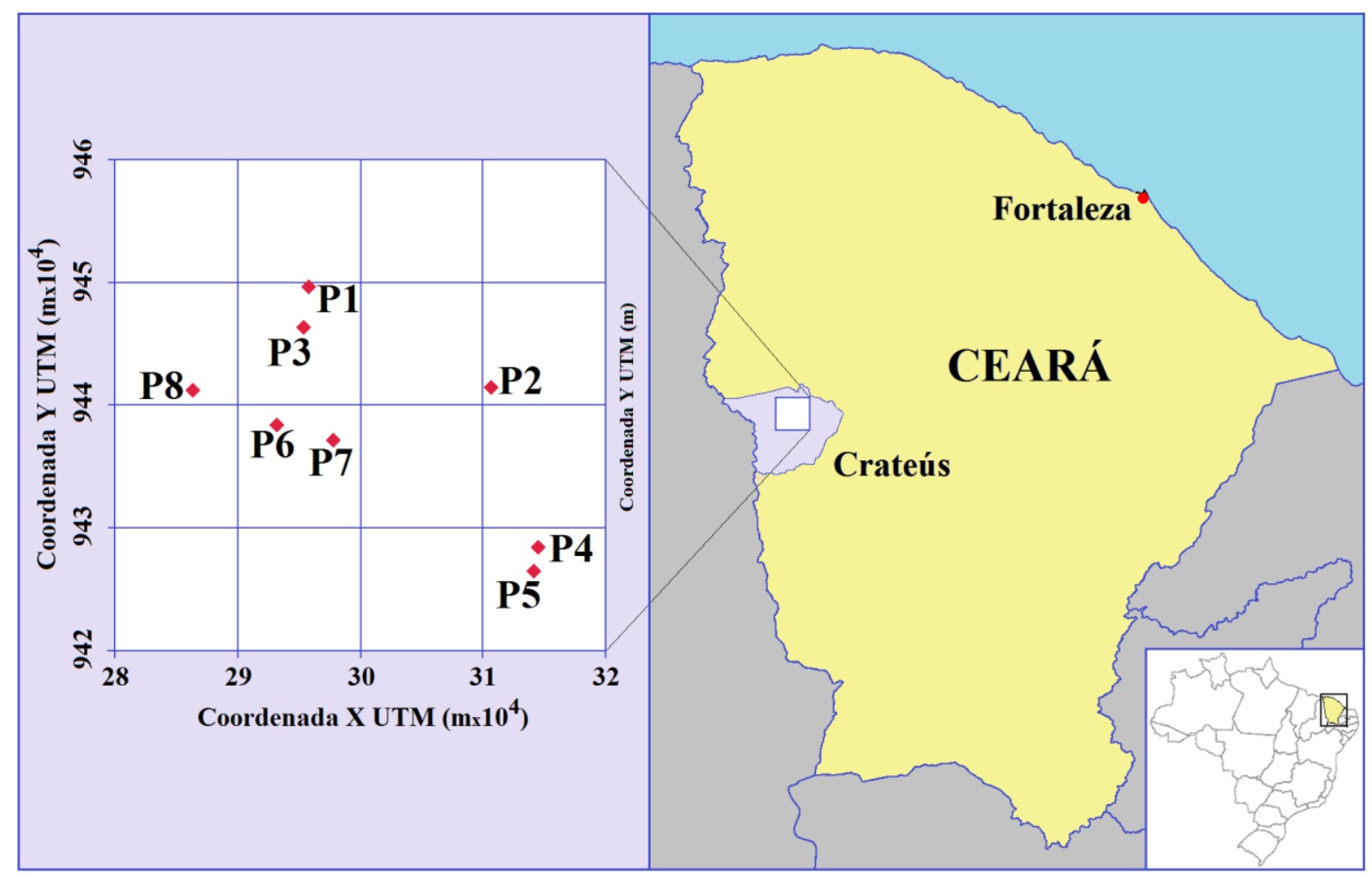

Figura 1. Localização dos oito poços estudados no município de Crateús, Estado do Ceará.

O clima da região é o tropical quente semiárido; o verão, estação seca, começa em junho e termina em janeiro. A temperatura nessa época do ano pode chegar a $40^{\circ} \mathrm{C}$. O inverno, estação chuvosa, começa em janeiro e se estende até maio com uma pluviometria média anual de $700 \mathrm{~mm}$ (Zavattini, 2004).

No município existem diversos açudes destacando-se, entre eles, o Realejo e o Carnaubal ou Grota Grande. Este último é o que aporta maior volume de água e abastece a população da sede do município (Brasil, 2010; Ceará, 2000).

\subsection{Procedimentos metodológicos}

Foram coletadas mensalmente, durante um período de doze meses (setembro de 2011 a agosto de 2012), amostras de água de oito poços amazonas para avaliar o $\mathrm{pH}$ e a concentração de íons carbonato $\left(\mathrm{CO}_{3}{ }^{2-}\right)$ e bicarbonato $\left(\mathrm{HCO}_{3}{ }^{-}\right)$das águas subterrâneas de Crateús. A localização geográfica dos poços amostrados está indicada na Figura 1 e Tabela 1. 
Tabela 1. Localização dos 08 (oito) poços monitorados nos 12 (doze) meses de pesquisa.

\begin{tabular}{cccccc}
\hline \multirow{2}{*}{ Poço } & \multirow{2}{*}{ Zona } & \multirow{2}{*}{ Comunidade } & \multirow{2}{*}{ Distrito } & \multicolumn{2}{c}{ Coordenadas UTM (m) } \\
\cline { 5 - 6 } P1 & Rural & Santa Clara & Assis & 295800 & Y \\
P2 & Rural & Curral Velho & Curral Velho & 310518 & 9449628 \\
P3 & Rural & Sede do distrito & Assis & 295440 & 94463509 \\
P4 & Urbana & Bairro São José & - & 314649 & 9428391 \\
P5 & Urbana & Bairro Planalto & - & 314253 & 9426423 \\
P6 & Rural & Cabaças & Poti & 293183 & 9438438 \\
P7 & Rural & Sede do distrito & Poti & 297808 & 9437008 \\
P8 & Rural & Sede do distrito & Ibiapaba & 286243 & 9441244 \\
\hline
\end{tabular}

As coletas foram realizadas obedecendo aos procedimentos descritos na NBR 9898/87 (ABNT, 1987). Acondicionadas em frascos de polietileno devidamente limpos, esterilizados e rotulados, as amostras foram conduzidas imediatamente ao laboratório onde as análises químicas eram efetuadas. Essa etapa da pesquisa foi realizada entre os dias 16 e 22 de cada mês.

A metodologia utilizada na realização dos procedimentos analíticos seguiu o Standard Methods. $\mathrm{O}$ pH de cada amostra foi medido no momento da coleta, utilizando-se um potenciômetro e, no laboratório, foram determinadas as concentrações dos íons carbonato e bicarbonato, utilizando o método titulométrico da alcalimetria (APHA et al., 2005).

Os resultados das análises químicas dos íons carbonato e bicarbonato foram inseridos numa planilha eletrônica elaborada especialmente para o tratamento desses dados, de modo que o cálculo das concentrações foi automático, diminuindo a margem de erro acidental.

Foram utilizados, para interpretação dos resultados das análises físico-químicas, as diretrizes traçadas nos trabalhos de Ayers e Westcot (1994) e Almeida (2010), que especificam as restrições impostas às águas subterrâneas destinadas ao uso na irrigação. Para consumo humano, foram usados os parâmetros da Portaria $n^{0}$ 2.914/11 do Ministério da Saúde (Brasil, 2011).

\section{RESULTADOS E DISCUSSÃO}

Os resultados das medidas do $\mathrm{pH}$ obtidas para as amostras analisadas nos 12 (doze) meses de pesquisa estão mostrados na Tabela 2 e na Figura 2. Os valores ficaram na faixa de 6,8 a 7,9, dentro do intervalo de 5,5 a 8,5 estabelecido na literatura para águas subterrâneas (Santos, 2008).

Tabela 2. Valores de pH nas amostras dos 08 (oito) poços monitorados nos 12 (doze) meses de pesquisa.

\begin{tabular}{ccccccccc}
\hline Mês/Ano & P1 & P2 & P3 & P4 & P5 & P6 & P7 & P8 \\
\hline Set/11 & 7,4 & 7,4 & 6,9 & 7,1 & 6,9 & 7,2 & 7,6 & 7,1 \\
Out/11 & 7,8 & 7,7 & 7,1 & 7,2 & 7,1 & 7,5 & 7,8 & 7,4 \\
Nov/11 & 7,6 & 7,5 & 7,1 & 7,2 & 7,1 & 7,3 & 7,8 & 7,4 \\
Dez/11 & 7,7 & 7,6 & 7,0 & 7,2 & 7,0 & 7,5 & 7,9 & 7,5 \\
Jan/12 & 7,8 & 7,7 & 7,1 & 7,4 & 7,2 & 7,6 & 7,9 & 7,4 \\
Fev/12 & 7,7 & 7,7 & 7,1 & 7,4 & 6,9 & 7,3 & 7,7 & 7,2 \\
Mar/12 & 7,7 & 7,5 & 7,0 & 7,4 & 6,8 & 7,5 & 7,9 & 7,3 \\
Abr/12 & 7,6 & 7,7 & 7,1 & 7,3 & 7,3 & 7,3 & 7,6 & 7,2 \\
Mai/12 & 7,7 & 7,4 & 7,0 & 7,4 & 6,8 & 7,4 & 7,8 & 7,2 \\
Jun/12 & 7,5 & 7,7 & 7,1 & 7,4 & 6,9 & 7,5 & 7,9 & 7,2 \\
Jul/12 & 7,6 & 7,6 & 7,3 & 7,5 & 6,8 & 7,4 & 7,8 & 7,3 \\
Ago/12 & 7,5 & 7,6 & 7,0 & 7,3 & 7,0 & 7,3 & 7,7 & 7,3 \\
\hline
\end{tabular}


No Gráfico 1 da Figura 2, observa-se que os valores mais elevados foram encontrados no P7 (7,9 nos meses de dezembro/11, janeiro, março e junho/12), distrito de Poti. Os menores valores $(6,8)$ foram registrados nas águas de P5, amostras dos meses de março, maio e julho/12; este poço está localizado no bairro Planalto.

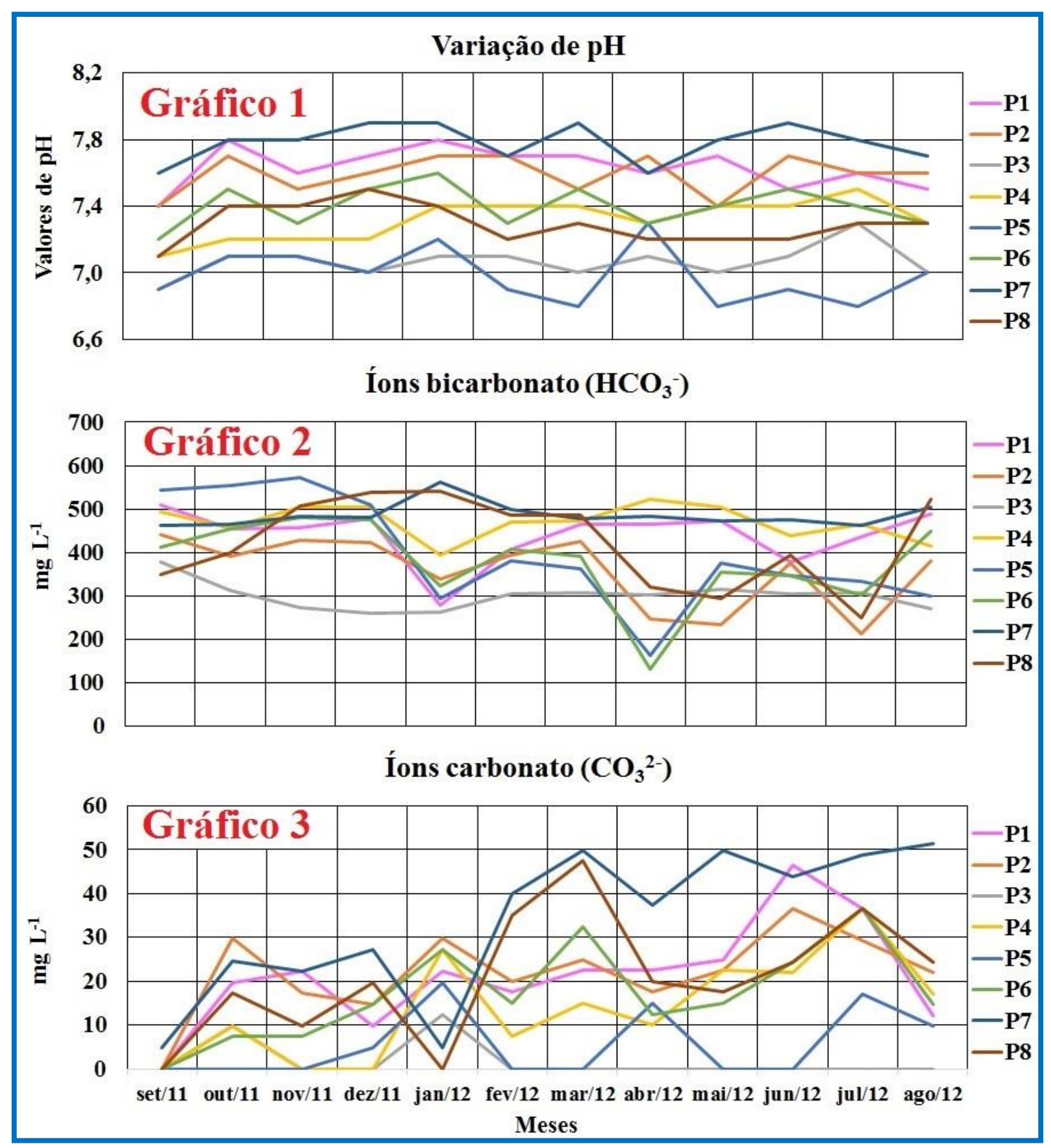

Figura 2. Gráficos mostrando a variação (1) do $\mathrm{pH}$ e das concentrações de (2) bicarbonato $\left(\mathrm{HCO}_{3}{ }^{-}\right)$e (3) carbonato $\left(\mathrm{CO}_{3}{ }^{2-}\right)$ das amostras dos 08 (oito) poços amazonas analisados durante os 12 (doze) meses de pesquisa.

Das 96 amostras, 7,3\% (7 amostras) apresentaram pH levemente ácido, com valores 6,8 ou 6,9; somente em 6,3\% (6 amostras) foram registrados valores de $\mathrm{pH}$ em torno de 7,0 (neutro). Em 86,4\% das amostras ( 83 delas), os valores de $\mathrm{pH}$ foram levemente alcalinos, variando entre 7,1 e 7,9. 
A maior variação anual do $\mathrm{pH}$ ocorreu nas águas do poço P5, mínimo 6,8 nas amostras de março, maio e julho/12 e o máximo 7,3 na amostra de abril/12. As menores variações foram registradas nos poços P2 e P7; o máximo de P2 foi 7,7 em outubro/11, janeiro, fevereiro, abril, junho/12, e o valor mínimo de 7,4 em setembro/11 e maio/12.

Considerando o $\mathrm{pH}$ medido nas amostras do primeiro e do último mês de análise (setembro/11 e agosto/12, respectivamente) em cada poço, observa-se que houve aumento em todos eles.

No entanto, estas variações no $\mathrm{pH}$ de todas as amostras estão dentro da faixa de 6,5 a 8,4, estabelecida por Ayers e Westcot (1994) como sem restrições quanto ao uso na irrigação. Segundo esses autores, águas com $\mathrm{pH}$ fora dessa faixa podem criar desequilíbrios de nutrição para os vegetais cultivados ou conter íons tóxicos às plantas. Todos os valores estão entre 6,0 e 9,5, portanto, dentro da faixa de $\mathrm{pH}$ determinada pela Portaria $\mathrm{n}^{\mathrm{o}}$ 2.914/11 do Ministério da Saúde para águas destinadas ao consumo humano (Brasil, 2011).

A Tabela 3 apresenta os dados referentes às análises químicas para o íon bicarbonato presente nas amostras estudadas. Segundo Santos (2008), a concentração de bicarbonato nas águas subterrâneas varia de 50,0 a 350,0 $\mathrm{mg} \mathrm{L}^{-1}$ em águas doces, em alguns casos pode chegar a $800,0 \mathrm{mg} \mathrm{L}^{-1}$.

Tabela 3. Concentração $\left(\mathrm{mg} \mathrm{L}^{-1}\right)$ de bicarbonato $\left(\mathrm{HCO}_{3}^{-}\right)$nas amostras dos 08 (oito) poços monitorados nos 12 (doze) meses de pesquisa.

\begin{tabular}{lcccccccc}
\hline Mês/Ano & P1 & P2 & P3 & P4 & P5 & P6 & P7 & P8 \\
\hline Set/11 & 510,2 & 442,3 & 377,0 & 492,6 & 542,9 & 412,2 & 462,5 & 349,4 \\
Out/11 & 454,9 & 392,1 & 311,7 & 457,4 & 552,9 & 454,9 & 465,0 & 399,6 \\
Nov/11 & 457,4 & 427,3 & 274,0 & 505,2 & 573,0 & 480,0 & 482,6 & 507,7 \\
Dez/11 & 477,5 & 422,2 & 258,9 & 505,2 & 510,2 & 475,0 & 480,0 & 537,9 \\
Jan/12 & 279,0 & 339,3 & 261,4 & 394,6 & 294,1 & 324,2 & 563,0 & 540,4 \\
Fev/12 & 408,2 & 393,0 & 304,3 & 469,1 & 380,3 & 408,2 & 499,5 & 486,8 \\
Mar/12 & 464,0 & 426,0 & 306,8 & 471,6 & 362,6 & 390,5 & 476,7 & 486,8 \\
Abr/12 & 464,0 & 245,9 & 301,7 & 522,3 & 162,3 & 131,9 & 484,3 & 319,5 \\
Mai/12 & 471,6 & 233,3 & 314,4 & 504,6 & 375,3 & 355,0 & 471,6 & 294,1 \\
Jun/12 & 377,5 & 375,0 & 305,5 & 439,6 & 347,7 & 347,7 & 474,4 & 394,9 \\
Jul/12 & 437,1 & 213,6 & 308,0 & 464,5 & 332,8 & 303,0 & 462,0 & 248,4 \\
Ago/12 & 489,3 & 380,0 & 270,7 & 414,8 & 300,5 & 449,6 & 504,2 & 521,6 \\
\hline
\end{tabular}

Como se observa na Tabela 3 e no Gráfico 2 da Figura 2, a maior concentração de bicarbonato foi encontrada no poço P5, na amostra do mês de novembro/11, com 573,0 mg L ${ }^{1}$, e a menor concentração no poço $\mathrm{P} 6$, com 131,9 $\mathrm{mg} \mathrm{L}^{-1}$, no mês de abril/12.

A maior variação do bicarbonato ocorreu no poço P5, que apresentou o valor mínimo de $162,3 \mathrm{mg} \mathrm{L}^{-1}$ na amostra de abril/12 e o máximo de $573,0 \mathrm{mg} \mathrm{L}^{-1}$ na amostra de novembro/11. A menor variação foi encontrada no poço $\mathrm{P} 7$, com máximo de $563,0 \mathrm{mg} \mathrm{L}^{-1}$ na amostra de janeiro/12 e mínimo de 462,0 $\mathrm{mg} \mathrm{L}^{-1}$ na amostra de julho/12.

Em geral, considerando os valores de bicarbonato nas amostras do primeiro e do último mês (setembro/11 e agosto/12, respectivamente) em cada poço, observa-se que houve aumento nos poços P6, P7 e P8 (37,5\%), e ocorreu diminuição na maioria dos poços trabalhados, P1, P2, P3, P4 e P5, isto é, em 62,5\% deles (Tabela 3, Gráfico 2 da Figura 2). O 
comportamento do bicarbonato difere do observado para o $\mathrm{pH}$, que apresentou aumento em todos os poços estudados (Tabela 2, Gráfico 1 da Figura 2).

Segundo a classificação de Ayers e Westcot (1994), quanto ao bicarbonato, 88 amostras $(91,7 \%)$ apresentaram restrições de leve a moderada para uso na agricultura, ou seja, elas podem provocar efeitos deletérios de natureza química, física ou biológica no solo e afetar negativamente o desenvolvimento das culturas.

Somente 08 amostras $(8,3 \%)$ apresentaram restrições severas, pois suas concentrações de bicarbonato excederam 518,5 $\mathrm{mg} \mathrm{L}^{-1}$, são elas: uma do poço P4 (abril/12), três do poço P5 (setembro a novembro/11), uma de P7 (janeiro/12) e três de P8 (dezembro/11, janeiro e agosto/12). Não é recomendável o uso dessas águas na agricultura, pois elas podem causar prejuízos aos vegetais cultivados. Nenhuma das amostras estudadas apresentou característica de água sem restrição de uso na irrigação.

Os valores das concentrações para o íon carbonato obtidos nas análises das amostras nos doze meses de pesquisa estão mostrados na Tabela 4. Do total de 96 amostras, 25 tiveram valores abaixo do limite de detecção da técnica analítica utilizada. Pelos resultados apresentados na Tabela 4 e no Gráfico 3 da Figura 2, observa-se que apenas no poço P7 foi detectado o íon carbonato em todas as suas amostras; são as águas que apresentaram os maiores valores de $\mathrm{pH}$.

Tabela 4. Concentração $\left(\mathrm{mg} \mathrm{L}^{-1}\right)$ de carbonato $\left(\mathrm{CO}_{3}{ }^{2-}\right)$ nas amostras dos 08 (oito) poços monitorados nos 12 (doze) meses de pesquisa.

\begin{tabular}{ccccccccc}
\hline Mês/Ano & P1 & P2 & P3 & P4 & P5 & P6 & P7 & P8 \\
\hline Set/11 & nd* & nd & nd & nd & nd & nd & 4,9 & nd \\
Out/11 & 19,8 & 29,7 & 9,9 & 9,9 & nd & 7,4 & 24,7 & 17,3 \\
Nov/11 & 22,3 & 17,3 & nd & nd & nd & 7,4 & 22,3 & 9,9 \\
Dez/11 & 9,9 & 14,8 & nd & nd & 4,9 & 14,8 & 27,2 & 19,8 \\
Jan/12 & 22,3 & 29,7 & 12,4 & 27,2 & 19,8 & 27,2 & 4,9 & nd \\
Fev/12 & 17,5 & 20,0 & nd & 7,5 & nd & 15,0 & 39,9 & 34,9 \\
Mar/12 & 22,5 & 24,9 & nd & 15,0 & nd & 32,4 & 49,9 & 47,4 \\
Abr/12 & 22,5 & 17,5 & nd & 10,0 & 15,0 & 12,5 & 37,4 & 20,0 \\
Mai/12 & 24,9 & 22,5 & nd & 22,5 & nd & 15,0 & 49,9 & 17,5 \\
Jun/12 & 46,4 & 36,6 & nd & 22,0 & nd & 24,4 & 44,0 & 24,4 \\
Jul/12 & 36,6 & 29,3 & nd & 36,6 & 17,1 & 36,6 & 48,9 & 36,6 \\
Ago/12 & 12,2 & 22,0 & nd & 17,1 & 9,8 & 14,7 & 51,3 & 24,4 \\
\hline
\end{tabular}

*nd = não detectado.

Nos poços P1, P2 e P6 não foi detectado carbonato no mês de setembro/11; nos poços P4 e P8 também não foi detectado em 3 amostras do primeiro (setembro, novembro e dezembro/11) e 2 amostras do segundo (setembro/11 e janeiro/12). No poço P3, o carbonato foi detectado somente nas amostras de outubro/11 e janeiro/12; no poço P5 em 5 amostras, em dezembro/11, janeiro, abril, julho e agosto/12 (Tabela 4 e Gráfico 3 da Figura 2). 
A maior concentração de carbonato foi detectada na amostra do mês de agosto/12 do poço $\mathrm{P} 7$, com o valor de $51,3 \mathrm{mg} \mathrm{L}^{-1}$ e a menor concentração, de $4,9 \mathrm{mg} \mathrm{L}^{-1}$, foi encontrada em 3 amostras: uma do poço P5, em dezembro/11, e duas do poço P7, em setembro/11 e janeiro/12.

A maior variação anual de íon carbonato ocorreu no poço P7, com valor mínimo 4,9 $\mathrm{mg} \mathrm{L}^{-1}$ nas amostras de setembro/11 e janeiro/12 e máximo de $51,3 \mathrm{mg} \mathrm{L}^{-1}$ na amostra de agosto/12. As menores variações foram registradas no poço $\mathrm{P} 3$, com valor máximo de $12,4 \mathrm{mg} \mathrm{L}^{-1}$ na amostra de janeiro/12 e o mínimo de $9,9 \mathrm{mg} \mathrm{L}^{-1}$ na amostra de outubro/11, mas o íon carbonato foi detectado em apenas 2 amostras deste poço.

As concentrações do íon carbonato em águas doces que apresentam valores de $\mathrm{pH}$ menores que 8,3 são inferiores às do íon bicarbonato, o que se observa comparando os dados das Tabelas 2 e 3 . O contrário só ocorrerá quando o $\mathrm{pH}$ assume valores maiores que 10 (Neven, 2006), o que não foi o caso de nenhuma das amostras estudadas (Tabela 2 e Gráfico 1 da Figura 2).

As concentrações dos íons bicarbonato e carbonato mostram que houve decréscimo nas concentrações do bicarbonato ao longo dos doze meses de pesquisa (Tabela 3), e aumento nas concentrações de carbonato nas águas de todos esses poços (Tabela 4).

Considerando as concentrações de carbonato (Tabela 4), das 96 amostras analisadas, 71,0 $\%$ (68 amostras) apresentaram valores acima de $6,0 \mathrm{mg} \mathrm{L}^{-1}$, significando que essas águas apresentam severas restrições ao seu uso na irrigação. Apenas 3,0 \% (1 amostra de P5, dezembro/11, e 2 de $\mathrm{P} 7$, setembro/11 e janeiro/12), tiveram concentração de carbonato entre 3,0 e 6,0 $\mathrm{mg} \mathrm{L}^{-1}$, portanto, apresentam restrições de leve a moderada.

Do total de amostras estudadas neste trabalho, 25 (26,0 \%) não foram avaliadas, devido a não detecção do íon carbonato.

Das poucas chuvas que precipitaram na região no período de desenvolvimento da pesquisa, as maiores intensidades ocorreram em janeiro/11 $(56 \mathrm{~mm})$ e no final de fevereiro/12 até início de abril/12 (75,7 mm) (FUNCEME, 2013). Essas chuvas, através da recarga, interferiram no equilíbrio das espécies químicas dissolvidas nas águas dos poços estudados, o que explica o comportamento dos valores das concentrações dos íons bicarbonato e carbonato.

Assim, enquanto nas águas de P3 e P4 (25,0 \%) a recarga provocou diminuição na concentração de bicarbonato até o mês de agosto/12, nas águas dos poços P1, P2, P5, P6, P7 e P8 $(75,0 \%)$ provocou aumento.

As concentrações de carbonato em P1, P2, P4, P5, P6 e P8 $(75,0 \%)$ decresceram neste mesmo período e, no poço $\mathrm{P} 7$, aumentaram de abril a agosto/12.

Considerações dessa natureza não podem ser aventadas para o poço P3, pois o íon carbonato foi detectado em apenas duas amostras.

\section{CONCLUSÕES}

Nenhuma das 96 amostras estudadas apresentou $\mathrm{pH}$ que comprometesse a qualidade das águas, ou seja, quanto a esse parâmetro hidroquímico, a utilização dessas águas não tem restrição, seja na irrigação ou para consumo humano.

No entanto, quanto aos outros dois parâmetros estudados, essas águas não podem ser usadas na agricultura sem devidos cuidados. Ao serem utilizadas na irrigação, devem ser monitoradas criteriosamente, necessitando de técnicas especiais de manejo, conforme o tipo de vegetal a ser cultivado. No caso das águas apresentando restrições severas, esses cuidados devem ser mais efetivos para amenizar os efeitos negativos na produtividade e no solo.

Os parâmetros bicarbonato e carbonato sofrem forte influência do clima semiárido. Como a estação chuvosa de 2012 foi atípica, com precipitação média anual na região em torno de 
130 mm (FUNCEME, 2013), muito abaixo do valor médio anual esperado (700 mm), não houve recarga suficiente para melhorar a qualidade da água desses poços.

Apesar destes parâmetros hidroquímicos se constituírem excelentes indicadores da qualidade da água, outros devem ser analisados para possibilitar uma avaliação mais criteriosa.

Pela simplicidade e baixo custo das técnicas analíticas utilizadas, na obtenção dos valores dos parâmetros aqui estudados, esta pesquisa se constitui a primeira etapa de procedimentos analíticos para conhecer a qualidade das águas.

\section{AGRADECIMENTOS}

Os autores agradecem à Fundação Cearense de Apoio ao Desenvolvimento Científico e Tecnológico (FUNCAP).

\section{REFERÊNCIAS}

ASSOCIAÇÃO BRASILEIRA DE NORMAS TÉCNICAS - ABNT. NBR 9898/1987: preservação e técnica de amostragem de efluentes líquidos e corpos receptores. Rio de Janeiro, 1987.

ALMEIDA, O. A. Qualidade da água de irrigação. Cruz das Almas: Embrapa Mandioca e Fruticultura, 2010. Disponível em: <http://www.cnpmf.embrapa.br/publicacoes/livro/ livro_qualidade_agua.pdf $>$. Acesso em: 07 mar. 2014.

ALVARENGA, L. A.; MARTINS, M. P. P.; CUARTAS, L. A.; PENTEADO, V. A.; ANDRADE, A. Estudo da qualidade e quantidade da água em microbacia, afluente do rio Paraíba do Sul - São Paulo, após ações de preservação ambiental. Revista Ambiente \& Água, v. 7, n. 3, p. 228-240, 2012. http://dx.doi.org/10.4136/ambiagua.987.

AMERICAN PUBLIC HEALTH ASSOCIATION - APHA; AMERICAN WATER WORKS ASSOCIATION - AWWA; WATER ENVIRONMENT FEDERATION - WEF. Standard methods for examination of water and wastewater. 21. ed. Washington, 2005. 1496 p.

AYERS, R. S.; WESTCOT, D. W. Water quality for agriculture. 3. ed. Roma: FAO, 1994. $153 \mathrm{p}$.

BRASIL. Ministério do Desenvolvimento Agrário. Plano territorial. Fortaleza, 2010. Disponível em: <http://sit.mda.gov.br/download/ptdrs/ptdrs_qua_territorio049.pdf>. Acesso em: 12 mar. 2013.

BRASIL. Ministério da Saúde. Portaria n. 2.914/2011. Brasília, 2011. 32 p. Disponível em: <http://portal.saude.gov.br/portal/arquivos/pdf/portaria_2914_ Acesso em: 19 jun. 2013.

12_12_2011.pdf>.

CEARÁ. Secretaria de Recursos Hídricos. Boletim informativo. Fortaleza, 2000. Disponível em: <http://www.cogerh.com.br/download/demon/SALINIDADE_ OUTUBRO2000. pdf>. Acesso em: 12 mar. 2013.

FEITOSA, F. A. C. Atlas digital dos recursos hídricos do Estado do Ceará. Fortaleza: CPRM, 1998. Disponível em: <http://www.cprm.gov.br/rehi/atlas/ceara/relatorios/ Crateus.zip>. Acesso em: 20 jul. 2013. 
FUNDAÇÃO CEARENSE DE METEOROLOGIA E RECURSOS HÍdRICOS FUNCEME. Calendário das chuvas no Estado do Ceará. Disponível em: $<$ http://www.funceme.br/index.php/areas/tempo/chuvas-diarias-municipios $>$. Acesso em: 07 ago. 2013.

LIMA, J. O. G.; FRANÇA, A. M. M.; LOIOLA, H. G. Implicações hidroquímicas da condutividade elétrica e do íon cloreto na qualidade das águas subterrâneas do semiárido cearense. Revista Virtual de Química, v. 6, n. 2, p. 279-292, 2014. http://dx.doi.org/10.5935/1984-6835.20140020

NEVEN, K. Hydrogeology and groundwater modeling. Boca Raton: CRC Press, $2006828 \mathrm{p}$.

REBOUÇAS, A. C. Água na região nordeste: desperdício e escassez. Estudos Avançados, v. 11, n. 29, p. 127-154, 1997. http://dx.doi.org/10.1590/S0103-40141997000100007.

SANTOS, A. C. Noções de hidroquímica. In: FEITOSA, F. A. C.; MANOEL FILHO, J.; DEMETRIO, J. G. (Orgs.). Hidrogeologia: conceitos e aplicações. 3. ed. Fortaleza: CPRM/REFO, LABHID-UFPE, 2008. p. 325-358.

SILVA JÚNIOR, L. G. A.; GHEYI, H. R.; MEDEIROS, J. F. Composição química de águas do cristalino do nordeste brasileiro. Revista Brasileira de Engenharia Agrícola e Ambiental, v. 3, n. 1, p. 11-17, abr. 1999.

TODD, D. K.; MAYS, L. W. Groundwater hydrology. 3. ed. New Jersey: Wiley, $2005.656 \mathrm{p}$.

TUCCI, C. E. M.; HESPANHOL, I.; NETTO, O. M. C. Cenários da gestão da água no Brasil: uma contribuição para a "Visão Mundial da Água". Revista Brasileira de Recursos Hídricos, v. 5, n. 3, p. 31-43, 2000.

ZAVATTINI, J. A. Estudos do clima no Brasil. 1. ed. Alínea: Campinas, 2004. 398 p.

ZOBY, J. L. G.; OLIVEIRA, F. R. Panorama da qualidade das águas subterrâneas no Brasil. Brasília: ANA, 2005. 74 p. Disponível em: <http://www.ana.gov.br>. Acesso em: 24 fev. 2010. 